\title{
Natural Mentors and Adolescent Resiliency: A Study With Urban Youth ${ }^{1}$
}

\author{
Marc A. Zimmerman ${ }^{2}$ and Jeffrey B. Bingenheimer \\ University of Michigan
}

Paul C. Notaro

University of Missouri

Natural mentors may play an important role in the lives of adolescents. We interviewed 770 adolescents from a large Midwestern city. Fifty-two percent reported having a natural mentor. Those with natural mentors were less likely to smoke marijuana or be involved in nonviolent delinquency, and had more positive attitudes toward school. Natural mentors had no apparent effect on anxiety or depression. Using the resiliency theory framework, natural mentors were found to have compensatory but not protective effects on problem behaviors, and both compensatory and protective effects on school attitudes. Direct and indirect (mediated) effects of natural mentors are explored for problem behaviors and school attitudes. The potential importance of natural mentors is supported, and implications for future research are considered.

KEY WORDS: adolescents; mentors; African American.

\footnotetext{
${ }^{1}$ This research was supported by the National Institute on Drug Abuse, Grant No. DA07484 to the first author. We thank PURA at the University of Michigan, Flint, for assistance with collecting the data; the Flint Community Schools for their support and cooperation; and the youth for sharing this information with us.

${ }^{2}$ To whom correspondence should be addressed at School of Public Health, University of Michigan, 1420 Washington Heights, Ann Arbor, Michigan 48109-2029; e-mail: marcz@ umich.edu.
} 


\section{INTRODUCTION}

Researchers have suggested that natural mentors may play a vital role in adolescent development (Blechman, 1992; Dondero, 1997; Hamilton \& Darling, 1996; Mech, Pryde, \& Rycraft, 1995; Rhodes, Contreras, \& Mangelsdorf, 1994; Rhodes, Ebert, \& Fischer, 1992). Young people often attribute their safe passage through the tumultuous years of adolescence to the influence of significant nonparental adults such as teachers, extended family members, or neighbors (Anderson, 1991; Lefkowitz, 1986; Smink, 1990). Moreover, several investigators studying adolescent resiliency have found that nonparental adults frequently have a positive effect by providing support to at-risk youth (Cowen \& Work, 1988; Luthar \& Zigler, 1991; Rhodes \& Jason, 1990; Werner \& Smith, 1982). The number of studies that examine the effects of natural mentors, however, is limited. While several researchers have provided evaluations of formal mentoring programs such as Big Brother/Big Sister (Mech et al., 1995; Nelson \& Valliant, 1993; Royce, 1998; Slicker \& Palmer, 1993; Tierney, Grossman, \& Resch, 1995), few have explored the natural mentor relationships that some adolescents form with nonparental adults in the course of their daily lives.

In recent years, however, researchers have started to focus attention upon the roles of natural mentors in adolescents' lives (Hamilton \& Darling, 1996; Rhodes et al., 1992, 1994). Some of this work has been devoted to characterizing these relationships in terms of prevalence, form, and function. Hamilton and Darling (1996), for example, studied 127 college students in an attempt to understand what kinds of students were likely to have mentors, what kinds of roles their mentors played in their lives, and what kinds of activities the mentors engaged in with them. They found that almost half $(45 \%)$ of their participants had an unrelated adult mentor, and that males were somewhat more likely than females to have one. They also found that mentors tended to perform teaching, challenging, and role modeling functions. Talking about personal and intellectual matters were the most common activities reported.

Investigators have also started to explore the connection between having a natural mentor and a variety of adolescent outcomes. Rhodes et al. (1992) studied 129 young African American mothers and found that those with natural mentors reported lower levels of depression. Moreover, they found that having a mentor moderated the relationship between depression and relationship problems, social support, and satisfaction with support. Adolescent mothers who had a mentor benefited more from the social support they received, and were less affected by relationship problems than were those who did not have a mentor. Similarly, Rhodes et al. (1994) studied 54 inner-city Latina adolescent mothers and found similar results. 
Latina adolescent mothers with a natural mentor reported lower levels of anxiety and depression, and greater satisfaction with the social support they received, compared to those without a mentor. They also found that having a mentor moderated the effects of relationship and support network problems on psychological distress. These studies, however, were based upon small and somewhat unique samples, and examined only a limited subset of the commonly investigated adolescent outcomes. Although they represent a promising start, research with larger samples and additional outcomes such as academic variables and problem behaviors may provide further insights into the role of natural mentors for adolescent development.

\section{Natural Mentors and Resiliency Theory}

Resiliency theory provides a framework for understanding why some youths who are exposed to a risk do not exhibit the problem behavior associated with that risk. This framework enables us to go beyond basic bivariate analyses to gain a more thorough understanding of the complicated relationships between risk factors, outcomes, and potentially helpful factors such as having a natural mentor.

Many adolescents who possess or experience a risk factor do not exhibit the negative outcome predicted by risk factor models. (Garmezy, 1991; Garmezy \& Masten, 1991; Masten, 1994; Rutter, 1987; Werner, 1993; Zimmerman \& Arunkumar, 1994). Other factors in youths' lives may counteract the effects of a given risk factor or may protect them from the negative consequences of risks. Two models of resiliency are particularly relevant for research on natural mentors: the compensatory and protective factor models (Garmezy, Masten, \& Tellegen, 1984; Zimmerman \& Arunkumar, 1994; Zimmerman, Steinman, \& Rowe, 1998).

The compensatory model of resiliency suggests that positive factors in an adolescent's life may counteract or neutralize the effects of risk factors. Having peers who use alcohol, for example, may increase the likelihood that an adolescent will use alcohol. This negative influence, however, may be counteracted by involvement in school or community organizations. In this model, the risk and compensatory factors both contribute in an additive fashion to the prediction of the outcome (Garmezy et al., 1984; Masten et al., 1988; Zimmerman et al., 1998). This model is typically tested in multiple linear regression by examining the main (direct) effects of having the compensatory factor when the risk factor is already included in the model (Zimmerman \& Arunkumar, 1994).

The protective factor model suggests that some factors may modify the relationship between risks and outcomes. These variables can operate 
as risk-protective or as protective-protective mechanisms (Brook, Brook, Gordon, \& Whiteman, 1990). A risk-protective variable functions by lessening the effect of a risk factor. That is, the effect of the risk factor depends upon whether or not (or the degree to which) a protective factor is present. For example, Zimmerman et al. (1998) found that the effect of having violent friends (risk factor) on adolescent males' violent behavior (negative outcome) was lower for youths who reported high levels of mother support (protective factor). In contrast, a protective-protective variable functions by increasing the effect of a compensatory factor. The effect of social support on psychological well-being, for example, may be enhanced by effective coping strategies. Risk-protective and protective-protective effects are typically represented by interaction terms in regression and other generalized linear models.

To test adequately the usefulness of resiliency models for describing the effects of having a natural mentor, we must first identify risk factors that are relevant to our outcomes of interest. We may then explore whether having a natural mentor compensates for or modifies their effects.

\section{Peer Influences on Adolescent Attitudes and Behavior}

Peers are one of the three primary socialization sources for adolescents (Oetting \& Donnermeyer, 1998). Socialization theory proposes that although peers can transmit both positive and negative norms to adolescents, they are the major source for adolescent deviance. Having friends who use alcohol and other drugs, for example, has been found to be a risk factor for an adolescent's own substance use (Ary, Tildesley, Hops, \& Andrews, 1993; Frauenglass, Routh, Pantin, \& Mason, 1997; Jenkins, 1996; Kandel, 1978; Williams \& Covington, 1997). Similarly, researchers have shown that other types of peer influence can be antecedents for many types of adolescent antisocial behavior. For instance, Reid (1987) found that adolescent drug use could be predicted primarily by the adolescent's association with drug-using peers. Peer smoking behavior has also been found to be a strong predictor of adolescent smoking behavior both directly and indirectly through normative pressure to smoke (Urberg, Shyu, \& Liang, 1990). In a longitudinal study, Ennett and Bauman (1991) found that peer attitudes toward drinking had direct effects on adolescents' drinking, and that peer drinking influenced adolescent's drinking through perceived norms about drinking. Frauenglass et al. (1997) examined both risk and protective factors for adolescent problem behaviors, and found that the deviant behaviors of peers were strongly associated with adolescent problem behaviors. These studies point out how 
both peer behaviors and peer attitudes may be primary socialization agents, especially when adolescent problem behaviors are of interest.

\section{This Study}

We examine the effects that natural mentors have on the lives of urban adolescents. Our study builds upon previous research in this area in several ways. First, our sample is larger and more heterogeneous than are previous studies, which helps to enhance statistical power and external validity. Second, we examine the effects of having a mentor on a wider range of outcomes. Although we explore some of the same psychological distress outcomes as previous researchers (Rhodes et al., 1992, 1994), we also include problem behaviors (e.g., alcohol use, marijuana use, and delinquent behavior) and attitudes toward school. Third, we use several analytical strategies to understand the nature of the relationships between having a natural mentor and our outcome variables. We focus our analyses on testing the compensatory and protective factor models of mentor support. Additionally, we test a mediated model to explore the direct and indirect effects of having a natural mentor.

\section{METHODS}

\section{Sample}

Participants included 770 adolescents who participated in the fourth wave (1997) of a longitudinal study of school dropout and drug use in a large Midwestern city. This represents a $90 \%$ response rate from the original (1994) sample of 850 youths. Students who were in their 1st year of high school in 1994, and who had eighth grade GPAs of 3.0 and below, were selected to participate. Students diagnosed as being either emotionally impaired or developmentally disabled were not included in the study. Females constituted $51.8 \%$ of the Year 4 respondents. The majority of participants were African American (79.6\%). The remainder were White (17.1\%) or biracial (3.2\%).

\section{Procedure}

Structured, face-to-face interviews were conducted with students in school during school hours by African American and White male and female 
Table I. Mean, Standard Deviation, Skew, and Cronbach Alpha for Study Variables

\begin{tabular}{lllrr}
\hline & $M$ & $S D$ & Skew & $\alpha$ \\
\hline Problem behaviors & & & & \\
$\quad$ Alcohol use & 5.13 & 3.84 & 0.64 & .83 \\
$\quad$ Marijuana use & 4.28 & 4.34 & 1.10 & .87 \\
$\quad$ Nonviolent delinquency & 1.23 & 0.45 & 3.09 & .83 \\
$\quad$ Violent behavior & 1.28 & 0.49 & 2.72 & .80 \\
$\quad$ School attitudes & & & & \\
$\quad$ School attachment & 2.92 & 0.64 & -0.48 & .81 \\
$\quad$ School importance & 4.35 & 0.54 & -1.35 & .73 \\
$\quad$ School efficacy & 4.43 & 0.65 & -1.33 & .86 \\
Psychological distress & 1.70 & 0.86 & 1.65 & .88 \\
$\quad$ Anxiety & 1.77 & 0.89 & 1.49 & .86 \\
$\quad$ Depression & & & & \\
Problem behavior risk factors & 1.93 & 0.73 & 0.84 & .86 \\
$\quad$ Friends' problem behaviors & 2.69 & 1.03 & -0.06 & .85 \\
$\quad$ Problem behavior norms & & & & \\
$\quad$ School attitude risk factors & 2.91 & 0.60 & 0.12 & .64 \\
$\quad$ Friends' school behaviors & 4.15 & 0.74 & -1.01 & .67 \\
$\quad$ School behavior norms & & & & \\
\hline
\end{tabular}

trained interviewers. Youths who could not be found in school were interviewed in a community setting (e.g., home, Urban League office). These interviews lasted 50-60 min. When the interview portion of the study was done, participants completed a self-administered pencil-and-paper questionnaire about drug and alcohol use. Participants were informed that all information was confidential and subpoena protected.

\section{Measures}

Summary statistics for all measures, including means, standard deviations, skewness, and Cronbach alphas are presented in Table I.

\section{Natural Mentor}

Participants were asked, "Is there an adult 25 years or older who you consider to be your mentor? That is, someone you can go to for support and guidance or if you need to make an important decision, or who inspires you to do your best?" Participants who responded in the affirmative were then asked, "What is his/her relationship to you?" If the respondent named a family member, they were then asked a second set of questions that were similar to the first but that specified "other than a family member (or the person who raised you)." Those who named someone other than an immediate 
family member on either of these questions were defined as having a natural mentor. Participants who said they had no mentor or who named only immediate family members (e.g., biological parents, siblings, stepparents) were defined as having no natural mentor. Thus, we created a dichotomous variable indicating for each participant whether she or he had a natural mentor. This operational definition of natural mentor is similar to those used by other researchers (Rhodes et al., 1992, 1994).

\section{Problem Behaviors}

Problem behaviors included four variables: alcohol use, marijuana use, nonviolent delinquent behavior, and violent behavior. Alcohol and marijuana use were measured by a sum of last year and last month use on a 7 -point Likert scale $(1=0$ times; $7=40$ or more times $)$. Participants answered these questions in a pencil-and-paper format following the face-toface interview. These items were the same as those used in the Monitoring the Future study (Johnston, O'Malley, \& Bachman, 1988). Nonviolent delinquency was assessed using frequency ratings for 10 nonviolent delinquent behaviors (e.g., theft, shoplifting, trespassing, arson, vandalism, selling drugs, trouble with police) during the past year. Violent behavior was assessed using frequency ratings for eight violent behaviors (e.g., assaulting teachers or supervisors, getting into fights, carrying a weapon, using a weapon to threaten others) in the past year. The violent and nonviolent delinquency items used 5 -point Likert scales $(1=0$ times; $5=4$ or more times $)$. Higher scores on these variables represent greater involvement in problem behaviors.

\section{School Attitudes}

School attitudes included three components: school efficacy, school importance, and school attachment. School attachment was assessed by seven items (e.g., "I do extra work on my own in class," "I like school," "Most mornings, I look forward to going to school.") using a 4-point Likert scale ranging from 1 (strongly disagree) to 4 (strongly agree; Hawkins, Catalano, \& Miller, 1992). School importance was assessed by another seven items (e.g., "I think being successful in school is important," "Going to school will help me reach my goals.") using a 5-point Likert scale ranging from 1 (not true) to 5 (very true; Roeser, Lord, \& Eccles, 1994). School efficacy was assessed by five items (e.g., "I can do even the hardest school work if I try," "Even if the work in school is hard, I can learn it.") using a 5-point Likert scale ranging from 1 (not true) to 5 (very true; Midgley, Maehr, \& Urdan, 1993). Higher scores on these variables represent more positive school attitudes. 


\section{Psychological Distress}

Psychological distress included anxiety and depression. Both measures included six items using a 5-point Likert scale. The items were taken from the Brief Symptom Inventory (Derogatis \& Spencer, 1982) and asked youths to indicate the frequency during the past week of various feelings (e.g., "nervousness or shakiness inside," "feeling fearful," "spells of terror or panic," "feeling lonely," "feeling no interest in things," "feeling hopeless about the future"). Higher scores on these variables represent greater psychological distress.

\section{Friends' Problem Behaviors}

Friends' problem behaviors were assessed by eight items. The questions asked about the number of the respondents' friends who had engaged in various behaviors (e.g., "drink beer or wine at least once a month," "smoke marijuana at least once a month," and "shoplift from stores"), and used 5 -point Likert scales $(1=$ None; $5=A l l)$. Higher scores on this variable represents greater exposure to peer problem behavior.

\section{Perceived Problem Behavior Norms}

Four items assessed respondents' perceptions of normative attitudes regarding problem behaviors (Eccles, 1993). These questions asked whether the respondents' friends would think it was cool or uncool if the respondent engaged in various behaviors (e.g., "Drank beer, wine, or liquor," "Used pot, marijuana, or other illegal drugs"). They used 5-point Likert scales ranging from 1 (Very Uncool) to 5 (Very Cool). The behaviors included alcohol use, drug use, smoking, and fighting. High scores on this variable represent increased exposure to social norms that are supportive of problem behaviors.

\section{Friends' School Behaviors}

Seven items were used to assess friends' school behaviors. Each item was a question regarding how many of the respondents' friends engaged in various school-related behaviors (e.g., "cut class-just don't go," "get all A or B grades," "Don't like most of their teachers"). These items were rated on a 5-point Likert scale from 1 (None) to $5(\mathrm{All})$. Higher scores on this variable thus represent increased exposure to peers' negative school behaviors. 


\section{Perceived School Attitude Norms}

Three items assessed respondents' perceptions of their friends' school attitudes (Eccles, 1993). These three items asked how friends would feel about the respondents' own school efforts and achievement (e.g., "Would your friends think it was cool or uncool if you got very good grades?") using a 5-point Likert scale $(1=$ Very Uncool; $5=$ Very Cool $)$. High scores on this variable represent greater exposure to school-supportive norms.

\section{Other Variables}

In addition to demographic characteristics such as race and sex, youths reported the occupations of both parents. Occupations were assigned a prestige score using Nakao and Treas' classification and rating scheme (Nakao $\&$ Treas, 1990a, 1990b). The highest occupational group received a score of 64.38 (professional), and the lowest group received a score of 27.84 (private household worker). If scores were available for both parents, the highest prestige score was used for analysis. Parents of youths in this sample were mostly blue-collar workers from the local factories. Overall, the mean prestige score was 39.96. It did not differ between the three racial groups, $F(2,675)=0.009, p=n s$, nor did it differ between Whites and African Americans when biracial youth were excluded from the analysis, $t(656)=$ $-0.100, p=n s$. The mean occupational prestige score was 39.94 for parents of African American youth, 40.04 for parents of White youth, and 40.17 for parents of mixed White and African American youth.

\section{Data Analytic Strategy}

Our data analytic strategy involves three stages. First, we use Multivariate Analysis of Variance (MANOVA; Bray \& Maxwell, 1982) to determine whether or not having a natural mentor was related to any of the adolescent outcomes we considered: problem behaviors, attitudes toward school, and psychological distress. In these models, we adjust for race and sex. For each set of outcomes, we first estimate a full model with all two- and three-way interactions. If no main effect of having a mentor was apparent in this analysis, we then estimate a main effects MANOVA, in which all interaction terms were omitted. For each statistically significant MANOVA, we examine the univariate statistics to determine which variables were associated with having a natural mentor. We then create a summary score to represent the set of dependent variables by standardizing and summing the variables that were 
statistically significant (at the $\alpha \leq .10$ level) in the univariate analysis. We use the resulting summary variables in subsequent analyses.

The second stage of our analysis tests the compensatory and protective effects of natural mentors. We use four-step linear regressions to accomplish this. In the first step, we enter demographic variables representing race, sex, and parents' occupational prestige. In the second step, we enter the friends/peers risk factor variable (e.g., friends' problem behaviors). In the third step, we add the mentor variable to the equation, and thereby test whether having a natural mentor fits the compensatory model of resiliency. If the additional amount of variance explained by adding the mentor variable to the model is significant, the compensatory model is supported. In the final stage, we enter a cross-product interaction term between the risk factor and the mentor variable into the regression model. This constitutes a test of the protective factor model of resiliency. If the interaction term explains a significant amount of additional variance, the protective factor model is supported. All independent variables are centered to minimize problems of multicollinearity.

In our last set of analyses we examine the direct and indirect (mediated) effects of natural mentors on our outcomes with the use of simple path models. We estimate four models, each corresponding to one of the regression analyses described earlier. The general structure of each model is shown in Fig. 1. Path A represents the direct effect of having a natural

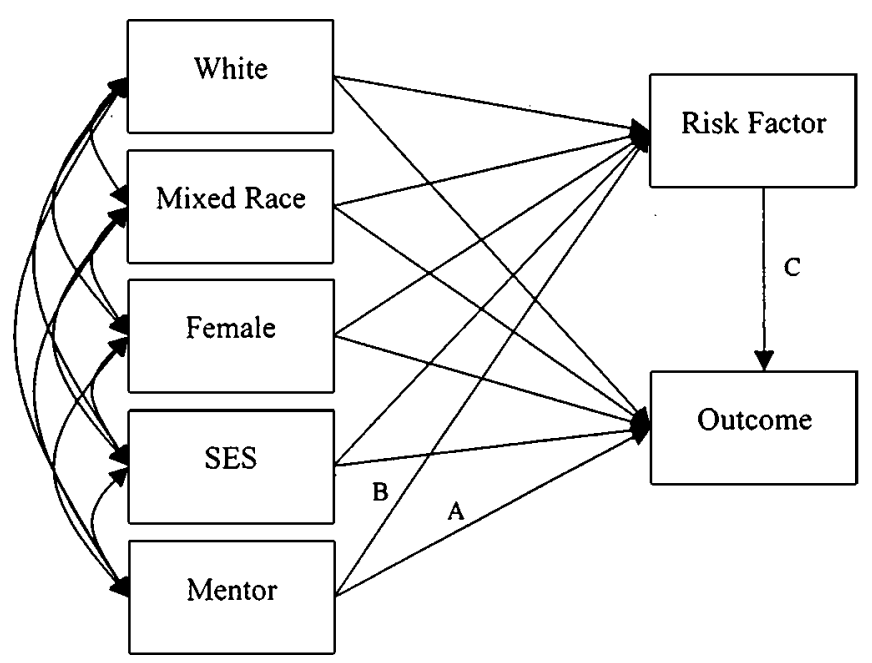

Fig. 1. Path model (estimated direct effects, Path A, and indirect effects, Path B and C, are presented in Table IV). 
mentor on our outcomes of interest (e.g., school attitudes). Path B represents the effect of having a natural mentor on the risk factor (e.g., exposure to friends' negative school attitudes). Path $\mathrm{C}$ represents the effect of the risk factor on the outcome. These models are based upon the theory that having a natural mentor may help young people by encouraging them to avoid risk factors (e.g., negative peer influences). The indirect effect on each outcome of having a natural mentor is simply product of Paths B and C. We used maximum likelihood to estimate the parameters in these structural equation models and thereby decomposed the effects of having a natural mentor into direct and indirect components. This decomposition of effects is equivalent to the method that Baron and Kenny (1986) outline for testing mediation.

\section{RESULTS}

Of the 770 adolescents participating in this study, 414 (53.8\%) reported having a natural mentor. The most commonly reported type of natural mentor in our sample was an extended family member, such as an aunt, uncle, cousin, or grandparent $(n=171,35.7 \%)$. Approximately $10 \%(n=48)$ of natural mentors were professionals, such as teachers, coaches, counselors, or ministers, whose mentoring relationship with the respondent may have evolved out of their professional duties. God-parents and god-siblings represented another commonly identified type of mentor, accounting for $6.7 \%$ $(n=32)$ of those identified. Other types of individuals identified as natural mentors included girlfriends and boyfriends of family members, as well as friends' parents and friends' siblings.

\section{Stage 1: MANOVA Analyses}

In the MANOVA analyses, we found that youths with natural mentors reported more positive school attitudes than did youth without natural mentors, Hotelling's $F(3,663)=10.88, p<.001$, adjusting for race, sex, and all two- and three-way interactions. Having a natural mentor was also associated with lower levels of problem behavior, Hotelling's $F(4,727)=2.96$, $p=.007$, when we adjusted for race and sex, but not when we included all two- and three-way interactions in the model, Hotelling's $F(4,720)=0.20$, $p=.939$. No association was found between having a natural mentor and psychological distress in either a main effects MANOVA model, Hotelling's $F(2,757)=0.16, p=.848$, or in a model including all two- and three-way interactions, Hotelling's $F(2,750)=2.78, p=.0630$. 
Table II. Means (and Standard Deviations) and Univariate $F$ Tests for All Outcome Variables Across Mentor Groups

\begin{tabular}{llll}
\hline & \multicolumn{2}{c}{$M(S D)$} & \\
\cline { 2 - 3 } & Mentor & No mentor & Univariate $F$ \\
\hline Problem behaviors & & & \\
$\quad$ Alcohol use & $4.84(3.69)$ & $5.45(3.98)$ & 1.77 \\
$\quad$ Marijuana use & $3.90(4.14)$ & $4.71(4.52)$ & $3.79^{*}$ \\
$\quad$ Nonviolent delinquency & $1.19(0.40)$ & $1.28(0.50)$ & $7.40^{* *}$ \\
$\quad$ Violent behavior & $1.27(0.49)$ & $1.29(0.50)$ & 0.39 \\
School attitudes & & & \\
$\quad$ School attachment & $3.03(0.59)$ & $2.78(0.66)$ & $32.38^{* * *}$ \\
$\quad$ School importance & $4.43(0.49)$ & $4.26(0.58)$ & $5.44^{* * *}$ \\
$\quad$ School efficacy & $4.51(0.59)$ & $4.33(0.71)$ & $3.00^{*}$ \\
Psychological distress & & & \\
$\quad$ Anxiety & $1.71(0.87)$ & $1.70(0.86)$ & 0.03 \\
$\quad$ Depression & $1.76(0.89)$ & $1.77(0.90)$ & 0.20 \\
\hline${ }^{*} p<.1 .{ }^{* *} p<.05 .{ }^{* * *} p<.01$. & & & \\
\end{tabular}

Univariate tests of the outcome variables are presented in Table II. Respondents in the mentor group reported less marijuana use and fewer nonviolent delinquent behaviors. They were also more likely to like school, to believe that success in school is important, and to feel capable of succeeding in school. In contrast, youths with and without natural mentors did not differ on the psychological distress variables.

Because this latter finding is not consistent with the results of previous research (Rhodes et al., 1992, 1994), we report the Sex $\times$ Mentor interaction results from the model with all two- and three-way interactions. We found no Sex $\times$ Mentor interaction effects, Hotelling's $F(2,750)=0.53 p=.587$. We also conducted the original MANOVA analysis separately for males and females and found no association between having a natural mentor and psychological distress in either group.

\section{Stage 2: Resiliency Models}

We conducted four sets of regressions to test the compensatory and protective effects of natural mentors. We did not include the psychological distress outcome in these models because the MANOVA analyses showed that having a natural mentor was unrelated to them. The summary problem behavior variable included marijuana use and nonviolent delinquency, but excluded alcohol use and violent behavior. The school attitudes summary variable included school attachment, school efficacy, and school importance. Table III presents results from these regression analyses, including partial $F$-tests and partial $R^{2} \mathrm{~s}$, final betas and final $R^{2} \mathrm{~s}$. 
Table III. Final Beta, $R^{2}$ Change, and $F$ Tests for Regression Analyses (Adjusted for Race, Sex, and Parents' Occupational Prestige)

\begin{tabular}{|c|c|c|c|}
\hline Predictor & Final $\beta$ & $F$ to enter & Change in $R^{2}$ \\
\hline \multicolumn{4}{|l|}{$\begin{array}{l}\text { Regression 1: Predicting problem behaviors } \\
\text { (final model } R^{2}=.248 \text { ) }\end{array}$} \\
\hline Step 1. Friends' problem behaviors & $.484^{* * *}$ & 182.01 & 211 \\
\hline Step 2. Mentor & $-.082^{* *}$ & 5.74 & .007 \\
\hline Step 3. Interaction & $-.035^{*}$ & 0.456 & .001 \\
\hline \multicolumn{4}{|l|}{$\begin{array}{l}\text { Regression 2: Predicting problem behaviors } \\
\text { (final model } R^{2}=.404 \text { ) }\end{array}$} \\
\hline Step 1. Problem behavior norms & $.657^{* * *}$ & 396.13 & .366 \\
\hline Step 2. Mentor & $-.079^{* *}$ & 6.71 & .006 \\
\hline Step 3. Interaction & $-.069^{*}$ & 2.45 & .002 \\
\hline \multicolumn{4}{|l|}{$\begin{array}{l}\text { Regression 3: Predicting school attitudes } \\
\text { (final model } R^{2}=.170 \text { ) }\end{array}$} \\
\hline Step 1. Friends's school behaviors & $-.382^{* * *}$ & 64.93 & .092 \\
\hline Step 2. Mentor & $.145^{* * *}$ & 13.86 & .019 \\
\hline Step 3. Interaction & $.122^{* *}$ & 4.31 & .006 \\
\hline \multicolumn{4}{|l|}{$\begin{array}{l}\text { Regression 4: Predicting school attitudes } \\
\text { (final model } R^{2}=.205 \text { ) }\end{array}$} \\
\hline Step 1. School attitude norms & $.413^{* * *}$ & 97.69 & 132 \\
\hline Step 2. Mentor & $.137^{* * *}$ & 12.77 & 017 \\
\hline Step 3. Interaction & $-.088^{*}$ & 2.78 & .004 \\
\hline
\end{tabular}

${ }^{*} p<.1{ }^{* *} p<.05 .{ }^{* * *} p<.01$.

We found main effects of both friends' problem behaviors, $F(1,654)=$ 182.01, $p<.01$, and problem behavior norms, $F(1,654)=396.13, p<.01$, for predicting respondents' problem behaviors. Having a natural mentor also predicted problem behaviors when friends' problem behaviors was in the model, $F(1,653)=5.74, p<.05$, as well as when perceived problem behavior norms was in the equation, $F(1,653)=6.71, p<.05$. The interaction term did not add further explanatory power in either equation, $F(1,652)=0.456$, $p=n s ; F(1,652)=2.45, p=n s$. Thus, for problem behavior outcomes, natural mentors appeared to fit the compensatory factor model of resiliency, but not the protective factor model.

Similarly, we found main effects of both friends' school behaviors, $F(1,602)=64.93, p<.01$, and school attitude norms, $F(1,602)=97.69$, $p<.01$, for predicting school attitudes. Main effects for mentors were also found when friends' school behaviors were in the model, $F(1,601)=13.86$, $p<.01$, and when perceived school norms were in the model, $F(1,601)=$ $12.77, p<.01$. In the model with friends' school behaviors as the risk factor, we found a Risk $\times$ Mentor interaction, $F(1,599)=4.31, p<.05$. The interaction term was marginally significant, $F(1,599)=2.78, p=.10$, in the model with school attitude norms as the risk factor. For school attitude outcomes, therefore, having a natural mentor fit both the compensatory and protective factor models of resiliency. 


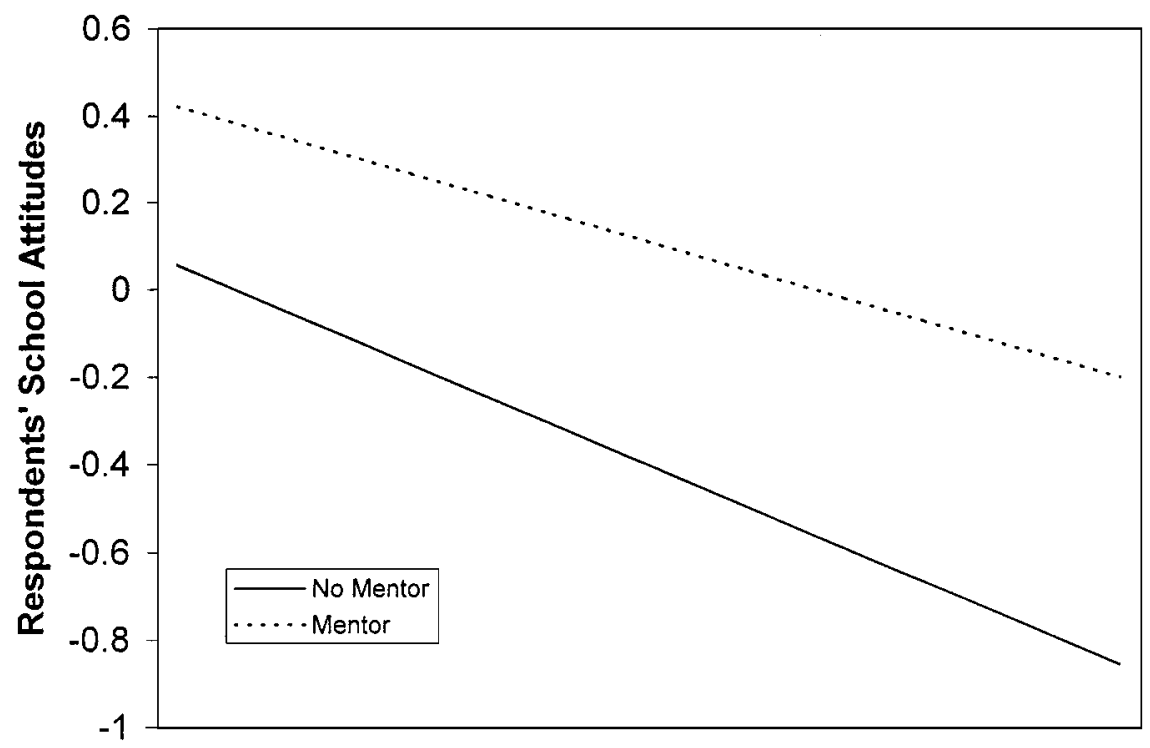

Friends' Negative School Behaviors

Fig. 2. Relationship between friends' negative school behaviors and respondents' school attitudes for the mentor and no mentor groups.

To facilitate interpretation of the statistical interactions, Figs. 2 and 3 present plots of the relationships between the risk factors (friends' negative school behaviors and perceived school attitude norms) and the dependent variable (respondents' school attitudes) for the mentor and no mentor groups, as implied by these regression models. Figure 2 shows that youth with natural mentors had more positive attitudes toward school across the range of friends' negative school behaviors. Moreover, the downward slope of the line for the mentor group is smaller than that for the no mentor group, indicating that youth with natural mentors were better able to maintain positive school attitudes even when they had friends whose school behaviors were negative. Figure 3 shows that, among respondents who perceived social norms that were supportive of school achievement, having a mentor made little difference. Among youth who did not perceive such positive norms, however, youth in the natural mentor group maintained more positive school attitudes than did youth without natural mentors, suggesting that natural mentors may have helped these youth maintain positive attitudes toward school even in a context in which school achievement was socially discouraged. 


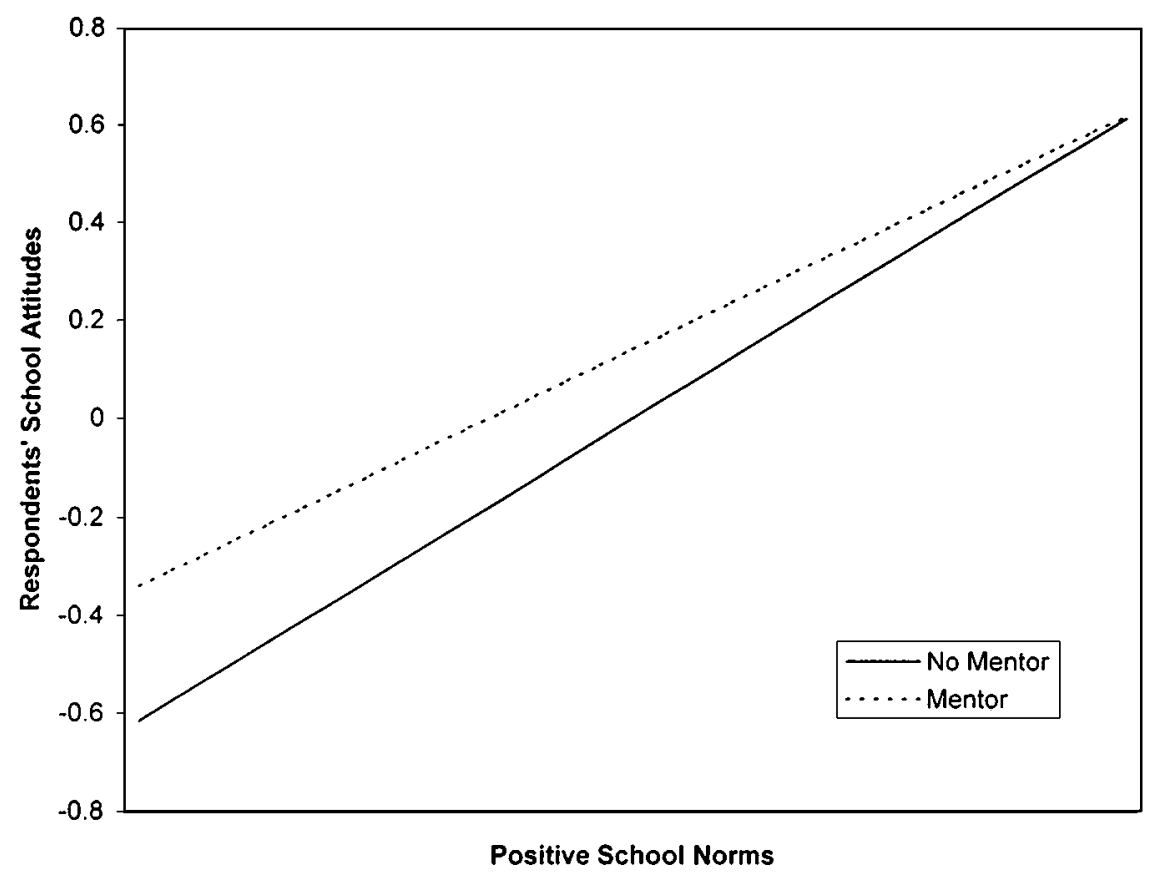

Fig. 3. Relationship between perceived positive school norms and respondents' school attitudes for the mentor and no mentor groups.

\section{Stage 3: Path Models}

We explored the direct and indirect effects of natural mentors in the next set of analyses. In these analyses, we hypothesized that mentors would have direct effects on our outcomes of interest, and would also have indirect effects that operate by reducing exposure to negative peer influences. As noted above, Fig. 1 shows the basic form of the path diagram. The results of these analyses are presented in Table IV.

We found direct effects of having a natural mentor on all of our outcomes, ranging in magnitude from .08 to .14 (in the standardized metric). Natural mentors had somewhat larger direct effects on school attitudes than they did on problem behaviors. The indirect effects of having a mentor were fairly similar in all four models, ranging in magnitude from .03 to .04. In three cases the indirect effects were statistically significant $(p \leq .05)$, and in one case it was marginally significant $(p=.076)$. Thus, for the problem behavior models, approximately one third of the effect of having a natural mentor may be indirect, operating by encouraging youths to avoid negative 
Table IV. Direct and Indirect (Mediated) Effects of Natural Mentors

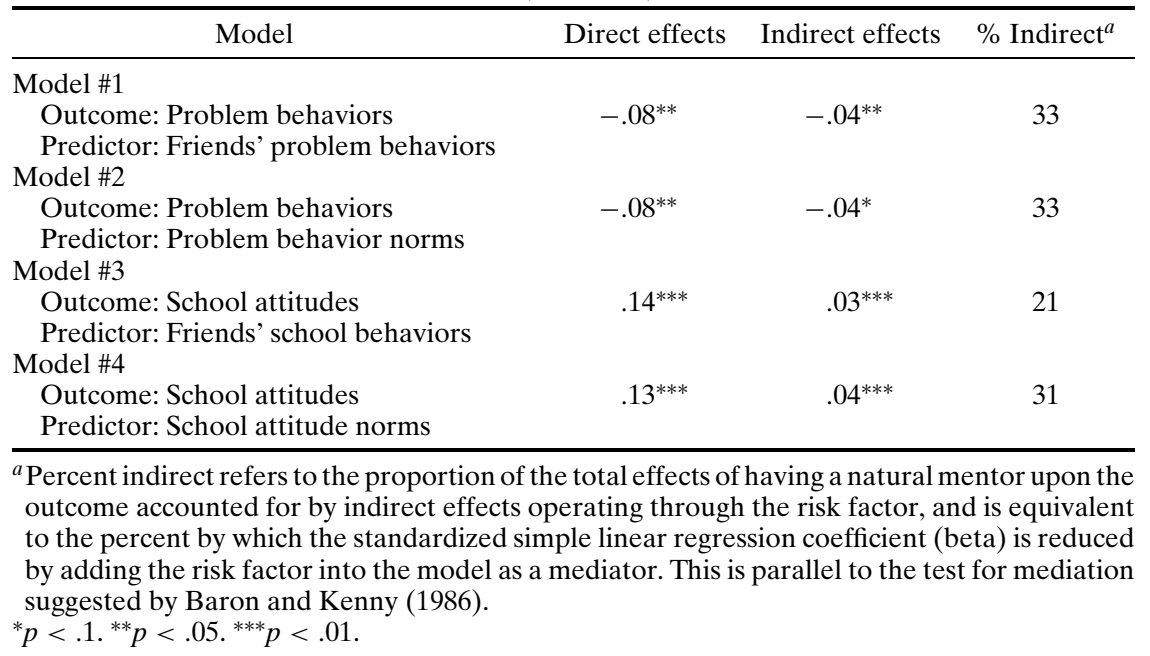

peer influences. For school attitude outcomes, such indirect effects (mediated by friends' school behaviors and school attitude norms), account for between one fifth and one third of the total effect of having a natural mentor on school attitudes.

\section{DISCUSSION}

This study contributes to our understanding of the role of natural mentors in adolescent development. We found empirical support for the proposition that having a natural mentor may play a vital role in the lives of adolescents. In our sample, substantial numbers of young people reported having adults whom they consider to be mentors. The proportion of adolescents who reported having a natural mentor was similar to what previous researchers have found among college students (Hamilton \& Darling, 1996), young African American mothers (Rhodes et al., 1992), and young Latina mothers (Rhodes et al., 1994).

We found that, overall, having a natural mentor was associated with a range of adolescent outcomes. Respondents who had natural mentors reported lower levels of marijuana use and nonviolent delinquency. Similarly, those with natural mentors reported higher levels of school attachment and school efficacy, and were more likely to believe in the importance of doing well in school. Notably, researchers have not studied these outcomes as they relate to natural mentoring. 
Somewhat surprisingly, we found no relationship between having a natural mentor and anxiety or depression. This was true when we included the entire sample in the analyses, and when we conducted the analyses separately for females and males. These results contradict the findings of previous researchers (Rhodes et al., 1992, 1994). Several factors may account for this discrepancy. First, previous researchers focused exclusively on young mothers, and it is possible that this constitutes a special subpopulation of adolescent females for whom natural mentors play a different role than do the youth in our study. Second, while we relied solely upon participants' own classification of people as mentors, previous researchers used operational definitions of natural mentor that focused more heavily upon social support. Respondents in these other studies who identified someone as a mentor but did not nominate her or him as a source of significant social support in another part of the interview were classified into the no mentor group (Rhodes et al., 1992, 1994). This classification scheme may have selected a subset of youth with natural mentors who differed systematically from other youth with natural mentors. Specifically, youth whose natural mentors play other roles but do not provide substantial social support may have been excluded from the natural mentor group, resulting in a natural mentor group that by definition received a large amount of social support. These points may not only explain why our findings are not consistent with those of previous research, but also highlight the need for ongoing work to clarify the conceptual definition of natural mentor and to develop ways of determining whether or not these figures are present in adolescents' lives.

Returning to problem behaviors and school attitudes, our results provide support for resiliency models of natural mentors' effects. For problem behavior outcomes, the compensatory model was supported, but the protective factor model was not. Respondents with natural mentors reported lower levels of problem behavior, including marijuana use and nonviolent delinquency, than did those without mentors. This was true even after we adjusted for demographic variables and known risk factors such as problem behavior norms and friends' problem behaviors. Having a mentor partially offset the effect of these negative peer influences, providing evidence of a compensatory effect. We did not, however, find significant interaction effects on problem behavior. A given increase in a risk factor resulted in the same increase in respondents' own problem behaviors, regardless of whether they reported having natural mentors.

Our results for school attitudes support both the compensatory and protective factor models of resiliency. When we considered friends' school behaviors and normative school attitudes as the risk factors, we found that having a natural mentor both offset (compensatory factor model) and modified (protective factor model) the effects of the risk factors. Youth with 
natural mentors had more positive school attitudes than did those without natural mentors. In addition, they were also less severely affected by the negative school attitudes or behaviors of their peers.

Our path analysis results suggest that natural mentors may not only have direct effects on reducing problem behaviors and increasing positive school attitudes, but may also have indirect effects by helping adolescents avoid peers who provide negative influences. In each of the four path models we estimated, these indirect effects accounted for one fifth to one third of the relationship between having a natural mentor and problem behaviors or school attitudes. These results suggest that, apart from promoting positive school attitudes and discouraging problem behaviors directly, natural mentors may encourage young people not to befriend peers who engage in problem behaviors or who discourage positive school attitudes.

A number of limitations of this study should be noted. First, the highest academic achieving youth (based upon eighth grade GPAs) were excluded from our sample. Truncating a sample in this way can threaten the internal and external validity of survey research (Berk, 1983). Several factors, however, may mitigate the problems associated with this sampling methodology. First, significant numbers of youth in our sample had GPAs above 3.0 in high school when the data for this study were collected (Zimmerman, Caldwell, \& Hilkene-Bernat, 2001). This suggests that substantial heterogeneity existed among respondents at the time the data were collected for this study. Second, our sample may adequately represent youths who are at increased risk for a range of negative outcomes (Gibbs, 1984; Zimmerman \& Arunkumar, 1994). If investigators wish to make inferences only about youth who are at increased risk for certain outcomes, it may be inappropriate to include high achieving youth in the sample. Examining factors within a sample that excludes higher achieving eighth graders may be helpful in understanding development among youth at greater risk for negative outcomes. Thus, our results may not generalize to all urban youth, but may be most relevant for those who are at greatest risk for negative outcomes because of lower school achievement prior to high school. Nevertheless, our sample is larger and more heterogeneous than studies by previous investigators of natural mentoring among adolescents (Hamilton \& Darling, 1996; Rhodes et al., 1992, 1994). In general, of course, care should be taken in generalizing our results, and special consideration should be given to the social and cultural context (urban, Midwestern, largely African American) within which our research was conducted.

A second limitation of this study is that we only examined the selfreported presence or absence of natural mentors in adolescents' lives, and the qualities of the mentor relationships were not assessed. Other approaches to measuring the presence or absence of natural mentors in adolescents 
lives have been used (Rhodes et al., 1992, 1994). In addition, Hamilton and Darling (1996) point out that natural mentor relationships are complex and may vary widely in terms of form, function, duration, and intensity. Future research may be enhanced by exploring whether findings are sensitive to different methods of creating dichotomous natural mentor variables, or by attempting to assess the full complexity of natural mentoring relationships. A more detailed measure of natural mentors that includes factors such as contact time, shared activities, and characteristics of the relationship may enable researchers to gain a richer understanding of the ways in which these relationships influence the lives of adolescents.

A third limitation of our study is that our data are all based upon selfreports. A consequence of using self-report measures is that observed associations between variables could be due to common method variance. In fact, one interpretation of our results is that method variance can explain the entire pattern of observed associations. Most variables were measured via self-report in face-to-face interviews. Drug and alcohol use, however, were measured using a self-administered questionnaire. If the tendency to provide socially desirable responses affected responses to interview questions more than responses to self-administered questions, one might expect stronger associations among interview questions than between interview questions and self-administered items. This could explain why the association between having a natural mentor and school attitudes was stronger than the association between having a natural mentor and problem behaviors, which included alcohol and other drug use. This limitation, however, characterizes most survey research, including previous research on natural mentoring. Nevertheless, future research would benefit from using other sources of data such as friends' ratings, mentors' reports, and school archival or administrative data.

It is also noteworthy that the effects we found were modest in magnitude. In our multiple regression models, the main effect of having a natural mentor generally accounted for less than $3 \%$ of the variation in our dependent variables. Moreover, in no case did the effects of mentor-by-risk factor interactions explain more than $1 \%$ of the variance in any outcome. The modest magnitude of these effects, however, does not necessarily mean they are unimportant. As Prentice and Miller (1992) point out, small effects may be considered impressive when the dependent variable is difficult to influence. Problem behaviors are widely known to be difficult to influence, and given that a large number of factors may be related to school attitudes it may be difficult for any one variable to have much influence on these as well. Moreover, statistically significant interaction effects are difficult to find in observational (as opposed to experimental) research (McClelland \& Judd, 1993). Our finding of interaction effects, in the case of school attitude 
outcomes, between peer risk factors and having a natural mentor suggests that a relatively powerful moderation effect may be operating.

Finally, we explored our hypotheses using only cross-sectional data. At best, our study may be thought of as a natural experiment in which selection into the treatment (natural mentor) and control (no natural mentor) groups is likely to be nonrandom. This does not provide a very solid basis for drawing causal inferences. The same variables that help determine whether or not an individual has a natural mentor may also affect problem behaviors and school attitudes. Therefore, while our data were consistent with a theoretical framework in which natural mentors help to reduce adolescents' problem behaviors and promote positive school attitudes, other frameworks may provide a different interpretation of the observed associations. Further research that accounts for selection effects such as personality factors of family processes may help distinguish spurious associations from true natural mentor effects.

Despite these limitations, this study contributes to the growing body of research suggesting that natural mentors may play a positive role in adolescent development. In our study, having a natural mentor appeared to be beneficial to adolescents for both problem behavior and school attitude outcomes. Yet, our results should not be interpreted as providing support for the effectiveness of formal mentoring programs. Specific studies to evaluate such programs are necessary to address that question. Several evaluations of mentoring programs have been reported with mixed results regarding their effectiveness (Mech et al., 1995; Nelson \& Valliant, 1993; Royce, 1998; Slicker \& Palmer, 1993; Tierney et al., 1995). The natural mentoring relationships that youth form with the nonparental adults with whom they interact in their daily lives may be quite different from the relationships they form with mentors to whom they are assigned through formal programs. Thus, organized mentoring programs and natural mentoring represent two distinct areas of research. Programs that create settings that provide opportunities for youth to interact with nonparental adults may help adolescents foster the development of natural mentoring relationships. Our results add to the growing literature that demonstrates the significance of these relationships for healthy adolescent development.

\section{REFERENCES}

Anderson, E. (1991). Neighborhood effects on teenage pregnancy. In C. Jencks \& P. E. Peterson (Eds.), The urban underclass (pp. 375-398). Washington, DC: Brookings Institution.

Ary, D. V., Tildesley, E., Hops, H., \& Andrews, J. (1993). The influence of parent, sibling, and peer modeling and attitudes on adolescent use of alcohol. The International Journal of the Addictions, 28, 853-880. 
Baron, R. B., \& Kenny, D. A. (1986). The moderator-mediator variable distinction in social psychological research: Conceptual, strategic, and statistical considerations. Journal of Personality and Social Psychology, 51, 1173-1182.

Berk, R. A. (1983). An introduction to sample selection bias in sociological data. American Sociological Review, 48, 386-398.

Blechman, E. A. (1992). Mentors for high-risk minority youth: From effective communication to bicultural competence. Journal of Clinical Child Psychology, 21, 160-169.

Bray, J. H., \& Maxwell, S. E. (1982). Analyzing and interpreting significant MANOVAs. Review of Educational Research, 52(3), 340-367.

Brook, J. S., Brook, D. W., Gordon, A. S., \& Whiteman, M. (1990). The psychosocial etiology of adolescent drug use: A family interactional approach. Genetic, Social, and General Psychology Monographs, 116, 111-267.

Cowen, E. L., \& Work, W. (1988). Resilient children, psychological wellness, and primary prevention. American Journal of Community Psychology, 16, 591-607.

Derogatis, L. R., \& Spencer, P. M. (1982). The Brief Symptom Inventory (BSI): Administration scoring and procedures manual-I. Baltimore, MD: Division of Medical Psychology, Johns Hopkins University School of Medicine.

Dondero, G. M. (1997). Mentors: Beacons of hope. Adolescence, 32, 881-886.

Eccles, J. (1993). Middle School Family Survey Study. Boulder: University of Colorado.

Ennett, S. T., \& Bauman, K. E. (1991). Mediators in the relationship between parental and peer characteristics and beer drinking in early adolescents. Journal of Applied Social Psychology, 21, 1699-1711.

Frauenglass, S., Routh, D. K., Pantin, H. M., \& Mason, C. A. (1997). Family support decreases influence of deviant peers on Hispanic adolescents' substance use. Journal of Clinical Child Psychology, 26(1), 15-23.

Gibbs, J. T. (1984). Black adolescents and youth: An endangered species. American Journal of Orthopsychiatry, 54, 6-21.

Garmezy, N. (1991). Resilience and vulnerability to adverse developmental outcomes associated with poverty. American Behavioral Scientist, 34, 416-430.

Garmezy, N., \& Masten, A. S. (1991). The protective role of competence indicators in children at risk. In E. M. Cummings, A. L. Green, \& K. H. Karraker (Eds.), Life-span developmental psychology: Perspectives on stress and coping (pp. 151-174). Mahwah, NJ: Erlbaum.

Garmezy, N., Masten, A. S., \& Tellegen, A. (1984). The study of stress and competence in children: A building block of developmental psychopathology. Child Development, 55, 97-111.

Hamilton, S. F., \& Darling, N. (1996). Mentors in adolescents' lives. In K. Hurrelmann \& S. F. Hamilton (Eds.), Social problems and social contexts in adolescence (pp. 121-139). Hawthorne, NY: Aldine.

Hawkins, J. D., Catalano, R. F., \& Miller, J. Y. (1992). Risk and protective factors for alcohol and other drug problems in adolescence and early adulthood: Implications for substance abuse prevention. Psychological Bulletin, 112, 64-105.

Jenkins, J. E. (1996). The influence of peer affiliation and student activities on adolescent drug involvement. Adolescence, 31(122), 297-306.

Johnston, L. D., O’Malley, P. M., \& Bachman, J. G. (1988). Illicit drug use, smoking, and drinking by America's high school students, college students, and young adults, 1975-1987. Rockville, MD: National Institute on Drug Abuse.

Kandel, D. B. (1978). Longitudinal research on drug use: Empirical findings and methodological issues. New York: Hemisphere.

Lefkowitz, B. (1986). Tough change: Growing up on your own in America. New York: Free Press.

Luthar, S. S., \& Zigler, E. (1991). Vulnerability and competence: A review of research on resilience in childhood. American Journal of Orthopsychiatry, 61, 6-22.

Masten, A. S. (1994). Resilience in individual development: Successful adaptation despite risk and adversity. In M. Wang \& E. W. Gordon (Eds.), Educational resilience in inner-city America (pp. 3-25). Mahwah, NJ: Erlbaum. 
Masten, A. S., Garmezy, N., Tellegen, A., Pelligrini, D. S., Larkin, K., \& Larsen, A. (1988). Competence and stress in schoolchildren: The moderating effects of individual and family qualities. Journal of Child Psychology and Psychiatry, 29, 745-764.

McClelland, G. H., \& Judd, C. M. (1993). Statistical difficulties of detecting interactions and moderator effects. Psychological Bulletin, 114, 376-390.

Mech, E. V., Pryde, J. A., \& Rycraft, J. R. (1995). Mentors for adolescents in foster care. Child and Adolescent Social Work Journal, 12, 317-328.

Midgley, C., Maehr, M. L., \& Urdan, T. (1993). Manuals for the Patterns of Adaptive Learning Survey (PALS). Ann Arbor: University of Michigan.

Nakao, K., \& Treas, J. (1990a). Computing 1989 occupational prestige scores (GSS Methodological Report No. 70). Chicago: National Opinion Research Center.

Nakao, K., \& Treas, J. (1990b). The 1989 socioeconomic index of occupations: Construction of the 1989 occupational prestige scores. (GSS Methodological Report No. 74). Chicago: National Opinion Research Center.

Nelson, C., \& Valliant, P. M. (1993). Personality dynamics of adolescent boys where the father is absent. Perceptual and Motor Skills, 76, 435-443.

Oetting, E. R., \& Donnermeyer, J. F. (1998). Primary socialization theory: The etiology of drug use and deviance. I. Substance Use and Misuse, 33, 995-1026.

Prentice, D. A., \& Miller, D. T. (1992). When small effects are impressive. Psychological Bulletin, 112, 160-164.

Rhodes, J. E., Contreras, J. M., \& Mangelsdorf, S. C. (1994). Natural mentors' relationships among Latino adolescent mothers: Psychological adjustment, moderating processes, and the role of early parental acceptance. American Journal of Community Psychology, 22, 211-228.

Rhodes, J. E., Ebert, L., \& Fischer, K. (1992). Natural mentors: An overlooked resource in the social networks of youth, African American mothers. American Journal of Community Psychology, 20, 445-462.

Rhodes, J. E., \& Jason, L. A. (1990). A social stress model of substance abuse. Journal of Consulting and Clinical Psychology, 58, 395-401.

Reid, L. D. (1987). Factors associated with the drug use of fifth through eight grade students. Journal of Drug Education, 17, 149-161.

Roeser, R. W., Lord, S. E., \& Eccles, J. (1994, February). A portrait of academic alienation in adolescence: Motivation, mental health, and family experience. Paper presented at the biennial meeting of the Society for Research on Adolescence, San Diego, CA.

Royce, D. (1998). Mentoring high-risk minority youth: Evaluation of the Brothers Project. Adolescence, 33, 145-158.

Rutter, M. (1987). Psychosocial resilience and protective mechanisms. American Journal of Orthopsychiatry, 57, 316-331.

Slicker, E. K., \& Palmer, D. J. (1993). Mentoring at-risk high school students: Evaluation of a school-based program. The School Counselor, 40, 327-334.

Sminck, J. (1990). Mentoring programs for at-risk youth: A dropout prevention research report. Clemson, SC: National Dropout Prevention Center.

Tierney, J. P., Grossman, J. B., \& Resch, N. L. (1995). Making a difference: An impact study. Philadelphia: Public/Private Ventures.

Urberg, K. A., Shyu, S. J., \& Liang, J. (1990). Peer influence in adolescent cigarette smoking. Addictive Behaviors, 15, 247-255.

Werner, E. E. (1993). Risk, resilience, and recovery: Perspectives from the Kauai Longitudinal Study. Development and Psychopathology, 5, 503-515.

Werner, E. E., \& Smith, W. (1982). Vulnerable but invincible: A study of resilient children. New York: McGraw-Hill.

Williams, J. G., \& Covington, C. J. (1997). Predictors of cigarette smoking among adolescents. Psychological Reports, 80, 481-482.

Zimmerman, M. A., \& Arunkumar, R. (1994). Resiliency research: Implications for schools and policy. Social Policy Report, 8, 1-18. 
Zimmerman, M. A., Caldwell, C. H., \& Bernat, D. H. (2002). Discrepancy between self-report and school record GPA: Correlates with psychosocial outcomes among African American adolescents. Journal of Applied Social Psychology, 32(1), 86-109.

Zimmerman, M. A., Steinman, K. J., \& Rowe, K. J. (1998). Violence among urban African American adolescents: The protective effects of parental support. In X. B. Arriaga \& S. Oskamp (Eds.), Addressing community problems: Psychological research and interventions (pp. 78-103). Thousand Oaks, CA: Sage. 